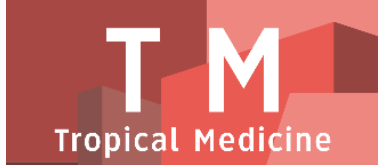

PAPER - OPEN ACCESS

\title{
Uji Aktivitas Antioksidan Ekstrak Etanol Fraksi N-Heksan Serta Fraksi Etil Asetat Daun Jamblang (Syzygium Cumini L. Skeels) Dengan Metode Dpph
}
Author
: Revi Septiani
DOI
: 10.32734/tm.v1i2.217
Electronic ISSN
: 2623-0550
Print ISSN
: 2623-0542

Volume 1 Issue 2 - 2018 TALENTA Conference Series: Tropical Medicine (TM)

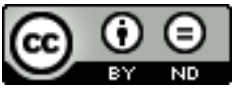

This work is licensed under a Creative Commons Attribution-NoDerivatives 4.0 International License.

Published under licence by TALENTA Publisher, Universitas Sumatera Utara
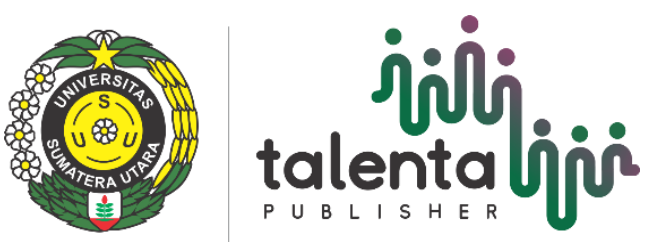


\title{
inili talenta ịio TALENTA Conference Series \\ P U B L I S H E R Available online at https://talentaconfseries.usu.ac.id \\ Uji Aktivitas Antioksidan Ekstrak Etanol Fraksi N-Heksan Serta Fraksi Etil Asetat Daun Jamblang (Syzygium Cumini L. Skeels) Dengan Metode Dpph
}

\author{
Revi Septiani $^{\mathrm{a}^{*}}$, Marianne ${ }^{\mathrm{a}}$, Marline Nainggolan ${ }^{\mathrm{a}}$ \\ ${ }^{a}$ Fakultas Farmasi, Universitas Sumatera Utara, Medan, Indonesia
}

reviseptiani8@gmail.com

\begin{abstract}
Abstrak
Jamblang (Syzygium cumini L. Skeels) merupakan salah satu tumbuhan famili Myrtaceae yang telah dikenal dan dimanfaatkan sebagai obat tradisional. Kandungan senyawa aktif dalam tanaman cukup banyak, diantaranya senyawa golongan polifenol yang merupakan salah satu sumber antioksidan alami. Daun jamblang sebagai senyawa antioksidan dapat diperoleh melalui ekstraksi dengan etanol dan difraksinasi dengan $n$-heksan serta etil asetat. Ekstrak dan fraksi daun jamblang diduga memiliki aktivitas menangkal radikal bebas terhadap DPPH. Penelitian ini bertujuan untuk membandingkan aktivitas antioksidan ekstrak etanol, fraksi n-heksan dan fraksi etil asetat dari daun jamblang. Ekstraksi dilakukan dengan metode maserasi menggunakan pelarut etanol 80\% dan difraksinasi dengan n-heksan dan etil asetat. Ekstrak dan fraksi diuji dengan metode pemerangkapan radikal bebas DPPH. Absorbansi DPPH diukur menggunakan spektrofotometer pada panjang gelombang $516 \mathrm{~nm}$ pada menit ke 15 setelah penambahan pelarut metanol. Ekstrak etanol memiliki nilai IC50 13,46 $\mu \mathrm{g} / \mathrm{mL}$, fraksi n-heksan 52,435 $\mu \mathrm{g} / \mathrm{mL}$, fraksi etil asetat 5,31 $\mu \mathrm{g} / \mathrm{mL}$ kategori sangat kuat dan untuk kuersetin memiliki IC50 sebesar 4,35 $\mu \mathrm{g} / \mathrm{mL}$. Fraksi n-heksan diklafikasikan kuat aktivitas antioksidannya sedangkan ekstrak etanol, fraksi etil asetat dan kuersetin diklasifikasikan sangat kuat. Hal tersebut menunjukan bahwa fraksi etil asetat memiliki aktivitas antioksidan yang paling tinggi dibanding pelarut lainnya.
\end{abstract}

Kata kunci : daun jamblang; fraksinasi, anitoksidan; DPPH; IC50

\section{Pendahuluan}

Penyakit tidak menular merupakan penyebab utama kematian secara global. Berdasarkan badan kesehatan dunia WHO, lebih dari dua pertiga (70\%) dari populasi global akan meninggal akibat penyakit tidak menular seperti kanker, penyakit jantung, dan diabetes. Angka kematian akibat penyakit ini diperkirakan akan terus meningkat diseluruh dunia sebanyak 52 juta jiwa pada tahun 2030[1]. Istilah antioksidan diketahui memiliki pengaruh positif bagi kualitas kesehatan manusia terutama kemampuannya dalam menetralisir dampak negatif dari radikal bebas [2].

Antioksidan merupakan atom atau molekul pemberi elektron yang dapat meredam dampak negatif radikal bebas. Antioksidan mampu menetralkan radikal bebas atau bahan yang dapat mencegah sistem biologi tubuh dari efek yang merugikan yang timbul dari proses ataupun reaksi yang menyebabkan oksidasi yang berlebihan [3]. 
Salah satu dari sekian banyak tumbuhan yang digunakan sebagai obat tradisional adalah tumbuhan jamblang Eugenia cumini Merr merupakan nama dulu dari Syzygium cumini) [4]. Daun jamblang mengandung glikosida, flavonol, kuersetin, mirisetin 3-O-4 asetil- L-ramnopiranosida, triterpenoid dan tanin [5].

Ruan et al. (2009) juga melakukan pengujian aktivitas antioksidan pada tanaman jamblang. Hasil pengujian menunjukkan ekstrak metanol daun jamblang memiliki aktivitas antioksidan (IC50 125,39 bpj) [6]. Lia marliani menggunakan pelarut air dengan IC50 sebesar $12,84 \mu \mathrm{g} / \mathrm{mL}$. Namun belum ada dilaporkan aktivitas antioksidan dengan menggunakan ekstrak etanol dan fraksinasi, sehingga peneliti tertarik untuk melakukan aktivitas antioksidan dari ekstrak etanol dan fraksinasi. Pada penelitian ini peneliti menguji aktivitas antioksidan menggunakan metode DPPH. Metode DPPH merupakan salah satu metode yang sederhana cepat, dan mudah untuk screening aktivitas antioksidan dari bahan makanan atau ekstrak suatu tumbuhan. Penelitian ini bertujuan untuk mengetahui perbandingan aktivitas antioksidan ekstrak etanol, fraksi n-heksan serta fraksi etil asetat daun jamblang (Syzygium cumini L. Skeels) dengan metode DPPH.

\section{Bahan dan Metode}

\subsection{Lokasi penelitian}

Penelitian ini dilakukan di Laboratorium Fitokimia dan Laboratorium Penelitian Fakultas Farmasi Universitas Sumatera Utara.

\subsection{Metode}

Penelitian ini dilakukan dari April 2017 sampai dengan Agustus 2017. Alat yang digunakan Maserator, penguap putar (Stuart), neraca analitis (Vibra), oven (Memmert), tanur (Gallenkamp), labu tentukur $50 \mathrm{~mL}$ (Oberoi), labu tentukur $10 \mathrm{~mL}$ (Oberoi), labu tentukur $5 \mathrm{ml}$ (oberoi), krus porselin, bola hisap (D\&N), spektrofotometer UV-Vis (Shimadzu UV-1800). Bahan yang digunakan dalam penelitian ini adalah : ekstrak etanol, fraksi n-heksan dan fraksi etil asetat daun jamblang, kuersetin, pelarut etanol $80 \%$, pelarut n-heksan, pelarut etil asetat, metanol p.a., DPPH (1,1diphenyl-2-picrylhydrazil). Identifikasi tumbuhan dilakukan diHerbarium Medanense (MEDA) Universitas Sumatera Utara.

\subsubsection{Karakterisasi simplisia dan ekstrak}

Pemeriksaan karakteristik simplisia seperti penetapan kadar air dilakukan menurut prosedur WHO (1992) [7]; pemeriksaan makroskopik, mikroskopik, penetapan kadar sari larut air, penetapan kadar sari larut etanol, penetapan kadar abu total dan penetapan kadar abu tidak larut asam dilakukan menurut prosedur yang terdapat dalam buku Materia Medika Indonesia [8].Skrining fitokimia serbuk simplisia daun jamblang meliputi pemeriksaan senyawa alkaloida, glikosida, saponin [9]; flavonoid, tanin, dan triterpenoid/ steroid [10].

\subsubsection{Pembuatan ekstrak etanol dan fraksinasi}

Serbuk simplisia daun jamblang dimaserasi dengan etanol 80\% selama 7 hari sambil sekali-sekali diaduk, kemudian disaring, dan filtrat yang diperoleh dikeringkan dengan alat penguap putar. Ekstrak etanol difraksinasi dengan nheksan membentuk dua lapisan lapisan n-heksana (lapisan atas) diambil, fraksinasi dilakukan sampai lapisan nheksana memberikan hasil negatif dengan pereaksi Liebermann-Burchard. Lapisan n-heksana yang dikumpulkan lalu dipekatkan dengan rotary evaporator sehingga diperoleh fraksi n-heksan. Perlakuan yang sama pada fraksinasi etil asetat memberikan hasil negatif dengan pereaksi $\mathrm{FeCl}$. Lapisan etil asetatat dikumpulkan dan dipekatkan dengan rotary evaporator sehingga diperoleh fraksi etil asetat.

\subsubsection{Pengujian aktivitas antioksidan dengan metode peredaman DPPH}

Kemampuan sampel uji dalam meredam radikal bebas DPPH dilihat dari perubahan warna DPPH dari ungu menjadi kuning dengan nilai IC50 (konsentrasi sampel uji yang mampu meredam radikal bebas sebanyak 50\%)yang digunakan sebagai parameter untuk menilai aktivitas antioksidan sampel uji. 


\subsubsection{Pengukuran larutan $D P P H$}

Dipipet larutan DPPH 0,5 mM sebanyak $1 \mathrm{~mL}$ kemudian dimasukkan ke dalam labu tentukur $5 \mathrm{~mL}$, dicukupkan dengan metanol sampai garis tanda (konsentrasi 40 ppm). Pengukuran dilakukan pada panjang gelombang 400-800 nm.

\subsubsection{Pembuatan larutan induk ekstrak, fraksi dan kuersetin}

Sebanyak $10 \mathrm{mg}$ ekstrak dan fraksi ditimbang kemudian masing-masing dilarutkan dalam labu tentukur $10 \mathrm{~mL}$ dengan metanol, lalu volumenya dicukupkan dengan metanol sampai garis tanda (konsentrasi 1000 ppm).

\subsubsection{Pengukuran aktivitas antioksidan}

LIB ekstrak etanol dipipet sebanyak $0,05 \mathrm{~mL} ; 0,1 \mathrm{~mL} ; 0,15 \mathrm{~mL} ; 0,2 \mathrm{~mL}$; kemudian dimasukkan ke dalam labu tentukur $10 \mathrm{~mL}$ (untuk mendapatkan konsentrasi 5 ppm, 10 ppm, 15 ppm dan 20 ppm).LIB fraksi n-heksan dipipet sebanyak 0,2 mL; 0,4 mL; 0,6 mL; 0,8 mL; kemudian dimasukkan ke dalam labu tentukur $10 \mathrm{~mL}$ (untuk mendapatkan konsentrasi $20 \mathrm{ppm}, 40 \mathrm{ppm}, 60 \mathrm{ppm}$, dan $80 \mathrm{ppm}$ ).LIB fraksi etil asetat dipipet sebanyak 0,02 mL; 0,04 mL;0,06 $\mathrm{mL} ; 0,08 \mathrm{~mL}$; kemudian dimasukkan ke dalam labu tentukur $10 \mathrm{~mL}$ (untuk mendapatkan konsentrasi $2 \mathrm{ppm}, 4$ ppm, $6 \mathrm{ppm}$ dan $8 \mathrm{ppm})$.

LIB kuersetin dipipet sebanyak 0,02 mL; 0,04 mL; 0,06 mL; dan 0,08 mL ke dalam labu tentukur $10 \mathrm{~mL}$ untuk mendapatkan konsentrasi larutan uji 2 ppm, 4 ppm, 6 ppm, dan 8 ppm.

Kemudian kedalam masing-masing labu tentukur ditambahkan $2 \mathrm{~mL}$ larutan induk baku (LIB) DPPH 0,5 mM, lalu volume dicukupkan dengan metanol sampai garis tanda dan dihomogenkan (masing-masing ekstrak dan fraksi diulangi dua kali dengan LIB yang berbeda). Pengukuran dilakukan setelah didiamkan selama 15 menit pada panjang gelombang $516 \mathrm{~nm}[11]$.

\subsubsection{Penentuan persen peredaman}

Kemampuan antioksidan diukur sebagai penurunan serapan larutan DPPH akibat adanya penambahan sampel. Nilai serapan larutan DPPH sebelum dan sesudah penambahan ekstrak dihitung sebagai persen peredaman (\%peredaman) dengan rumus sebagai berikut:

\% peredaman = ("A" _"kontrol" "- " "A" _"sampel" )/"A" _"kontrol" x100\%

Keterangan:

Akontrol $=$ Absorbansi tidakmengandung sampel

Asampel $=$ Absorbansi sampel

Selanjutnya hasil perhitungan dimasukkan ke dalam persamaan regresi dengan konsentrasi ekstrak (ppm) sebagai absis (sumbu X) dan nilai \% peredaman (antioksidan) sebagai ordinatnya (sumbu Y).

\section{Hasil}

\subsection{Hasil identifikasi tumbuhan}

Hasil identifikasi tumbuhan yang dilakukan di Herbarium Medanense (MEDA) Universitas Sumatera Utara menunjukkan bahwa tumbuhan yang diteliti adalah tumbuhan jamblang ( Syzigium cumini L. Skeel) suku Myrtaceae.

\subsection{Hasil pemeriksaan karakteristik serbuk simplisia dan ekstrak}

Penetapan kadar air dari simplisia daun jamblang diperoleh 7,94\%. Penetapan kadar sari yang larut dalam air diperoleh $15,58 \%$. Penetapan kadar sari yang larut dalam etanol diperoleh 15,92\%. Penetapan kadar abu total diperoleh 6,06\%. Penetapan kadar abu tidak larut asam diperoleh 0,83\%. Penetapan kadar air dari ekstrak etanol daun jamblang 6,61\%. Penetapan kadar abu total diperoleh 4,71\%. Penetapan kadar abu tidak larut asam diperoleh $0,75 \%$. 


\subsection{Hasil skrining fitokimia serbuk simplisia}

Hasil skrining fitokimia simplisia dan ekstrak etanol daun jamblang menunjukkan adanya senyawa kimia golongan flavonoid, glikosida, saponin, tanin dan triterpenoid/steroid. Fraksi n-heksan terdapat senyawa triterpenoid/steroid dan fraksi etil asetat menunjukan adanya senyawa golongan flavonoid, glikosida, saponin dan tanin. Hal ini menunjukan bahwa daun jamblang berpotensi sebagai antioksidan. Senyawa yang mempunyai potensi sebagai antioksidan yaitu flavonoid, tanin. Senyawa tersebut bertindak sebagai penangkap radikal bebas karena gugus hidroksil yang dikandungnya mendonorkan hidrogen kepada radikal bebas[12].Selain itu senyawa steroid juga mempunyai potensi sebagai antioksidan. Hal ini didukung berdasarkan penelitian oleh Cui yang menyatakan bahwa ekstrak etanol $80 \%$ dari inonotus obliquus yang positif mengandung steroid seperti lanosterol dan ergosterol peroksida menghasilkan aktivitas antioksidan sekunder radical scavenger yang cukup aktif [13].

\subsection{Hasil ekstraksi dan fraksinasi}

Hasil ekstraksi simplisia daun jamblang 300 (g) menggunakan pelarut etanol 80\% diperoleh ekstrak etanolnya sebanyak 67,731 g. Fraksi n-heksan 11,90 g dan fraksi etil asetat 11,95 g. Ekstrak dan fraksiyang diperoleh diuji aktivitas antioksidan dengan metode pemerangkapan/ peredaman radikal bebas DPPH.

\subsection{Analisis aktivitas antioksidan metode pemerangkapan radikal bebas DPPH}

Aktivitas antioksidan ektrak etanol dan fraksi diperoleh dari hasil pengukuran absorbansi DPPH pada menit ke-15. Hasil uji aktivitas antioksidan ekstrak etanol dan fraksi serta pembanding secara kuantitatif dapat dilihat pada tabel dan gambar berikut :

Tabel 1. Aktivitas penangkap radikal DPPH dari Ekstrak Etanol Daun Jamblang

\begin{tabular}{|c|c|c|c|c|c|c|}
\hline No & $\begin{array}{l}\text { Konsentrasi } \\
\quad(\mathrm{ppm})\end{array}$ & Absorbansi & $\begin{array}{l}\text { Peredaman } \\
\text { DPPH oleh } \\
\text { ekstrak (\%) }\end{array}$ & $\begin{array}{c}\text { Persamaan Regresi } \\
\text { Linier }\end{array}$ & Korelasi & $\mathrm{IC}_{50}$ \\
\hline \multirow[t]{5}{*}{ I } & 0 & 0,991 & 0 & $Y=3,778 x-1,132$ & $\mathrm{R}=0,998$ & 13,53 \\
\hline & 5 & 0,826 & 16,61 & & & \\
\hline & 10 & 0,627 & 36,73 & & & \\
\hline & 15 & 0,453 & 54,29 & & & \\
\hline & 20 & 0,242 & 75,61 & & & \\
\hline \multirow[t]{6}{*}{ II } & 0 & 0,991 & 0 & $Y=3,8 x-0,936$ & $\mathrm{R}=0,999$ & 13,4 \\
\hline & 5 & 0,822 & 17,05 & & & \\
\hline & 10 & 0,622 & 37,2 & & & \\
\hline & 15 & 0,445 & 55,09 & & & \\
\hline & 20 & 0,238 & 75,98 & & & \\
\hline & & & Rata-rata & & & 13,46 \\
\hline
\end{tabular}

Tabel 2. Aktivitas penangkap radikal DPPH dari Fraksi n-heksan Daun Jamblang

\begin{tabular}{|c|c|c|c|c|c|c|}
\hline No & $\begin{array}{l}\text { Konsentrasi } \\
\quad(\mathrm{ppm})\end{array}$ & Absorbansi & $\begin{array}{l}\text { Peredaman } \\
\text { DPPH oleh } \\
\text { ekstrak }(\%)\end{array}$ & $\begin{array}{c}\text { Persamaan Regresi } \\
\text { Linier }\end{array}$ & Korelasi & $\mathrm{IC}_{50}$ \\
\hline \multirow[t]{5}{*}{ I } & 0 & 0,991 & 0 & $\mathrm{Y}=0,951 \mathrm{x}-0,842$ & $\mathrm{R}=0,999$ & 53,43 \\
\hline & 20 & 0,815 & 17,73 & & & \\
\hline & 40 & 0,626 & 36,79 & & & \\
\hline & 60 & 0,444 & 55,12 & & & \\
\hline & 80 & 0,233 & 74,46 & & & \\
\hline II & 0 & 0,991 & 0 & $Y=0,981 x-0,504$ & $\mathrm{R}=0,999$ & 51,44 \\
\hline
\end{tabular}




$\begin{array}{lll}20 & 0,809 & 18,33 \\ 40 & 0,604 & 39,05 \\ 60 & 0,414 & 58,25 \\ 80 & 0,216 & 78,23\end{array}$

Tabel 3. Aktivitas penangkap radikal DPPH dari fraksi etil asetat Daun Jamblang

\begin{tabular}{|c|c|c|c|c|c|c|}
\hline No & $\begin{array}{l}\text { Konsentrasi } \\
(\mathrm{ppm})\end{array}$ & Absorbansi & $\begin{array}{l}\text { Peredaman } \\
\text { DPPH oleh } \\
\text { ekstrak (\%) }\end{array}$ & $\begin{array}{l}\text { Persamaan Regresi } \\
\text { Linier }\end{array}$ & Korelasi & $\mathrm{IC}_{50}$ \\
\hline \multirow[t]{5}{*}{$\mathrm{I}$} & 0 & 0,991 & 0 & $Y=9,631 x-1,128$ & $\mathrm{R}=0,997$ & 5,32 \\
\hline & 2 & 0,827 & 16,55 & & & \\
\hline & 4 & 0,618 & 37,67 & & & \\
\hline & 6 & 0,417 & 54,86 & & & \\
\hline & 8 & 0,226 & 77,16 & & & \\
\hline \multirow[t]{6}{*}{ II } & 0 & 0,991 & 0 & $Y=9,649 x-1,224$ & $\mathrm{R}=0,998$ & 5,3 \\
\hline & 2 & 0,825 & 16,78 & & & \\
\hline & 4 & 0,618 & 37,61 & & & \\
\hline & 6 & 0,444 & 55,19 & & & \\
\hline & 8 & 0,225 & 77,29 & & & \\
\hline & & & Rata-rata & & & 5,31 \\
\hline
\end{tabular}

Tabel 4. Aktivitas penangkap radikal DPPH dari kuersetin

\begin{tabular}{|c|c|c|c|c|c|c|}
\hline No & $\begin{array}{l}\text { Konsentrasi } \\
\quad(\mathrm{ppm})\end{array}$ & Absorbansi & $\begin{array}{l}\text { Peredaman } \\
\text { DPPH oleh } \\
\text { ekstrak (\%) }\end{array}$ & $\begin{array}{c}\text { Persamaan Regresi } \\
\text { Linier }\end{array}$ & Korelasi & $\mathrm{IC}_{50}$ \\
\hline \multirow[t]{5}{*}{ I } & 0 & 0,991 & 0 & $Y=11,52 x-0,272$ & $\mathrm{R}=0,998$ & 4,36 \\
\hline & 2 & 0,756 & 23,64 & & & \\
\hline & 4 & 0,559 & 43,59 & & & \\
\hline & 6 & 0,301 & 69,63 & & & \\
\hline & 8 & 0,077 & 92,23 & & & \\
\hline \multirow[t]{6}{*}{ II } & 0 & 0,991 & 0 & $Y=11,48 x-0,108$ & $\mathrm{R}=0,997$ & 4,34 \\
\hline & 2 & 0,743 & 25,03 & & & \\
\hline & 4 & 0,566 & 42,81 & & & \\
\hline & 6 & 0,297 & 69,99 & & & \\
\hline & 8 & 0,076 & 92,33 & & & \\
\hline & & & Rata-rata & & & 4,35 \\
\hline
\end{tabular}

Tabel 5. Kategori nilai $\mathrm{IC}_{50}$ sebagai antioksidan

\begin{tabular}{ll}
\hline Sampel & Kategori \\
\hline Ekstrak etanol & Sangat Kuat \\
Fraksi n-heksan & Kuat \\
Fraksi etil asetat & Sangat Kuat \\
Kuersetin & Sangat Kuat \\
\hline
\end{tabular}




\section{Pembahasan}

Hasil pada Tabel dan gambar diatas menunjukkan bahwa ekstrak etanol, fraksi n-heksan, fraksi etil asetat dan pembanding memiliki aktivitas antioksidan yang berbeda satu dengan yang lain. Hasil analisis peredaman radikal bebas oleh ekstrak dan fraksi menunjukkan bahwa kenaikan konsentrasi berbanding lurus dengan peningkatan persen peredaman karena semakin banyak atom hidrogen dari ekstrak etanol, fraksi n-heksan dan fraksi etil asetat daun jamblang yang berpasangan dengan elektron pada radikal bebas DPPH sehingga serapan semakin menurun yang ditandai dengan berubahnya warna larutan menjadi kuning [11]. Ekstrak etanol daun jamblang memiliki aktivitas antioksidan yang sangat kuat dengan nilai IC50 rata-rata sebesar 13,46 $\mu \mathrm{g} / \mathrm{mL}$, fraksi n-heksan nilai IC50 sebesar $52,435 \mu \mathrm{g} / \mathrm{mL}$ dikategorikan kuat dan fraksi etil asetat memiliki aktivitas antioksidan yang sangat kuat dengan nilai IC50 sebesar 5,31 $\mu \mathrm{g} / \mathrm{mL}$ serta kuersetin nilai IC50 sebesar $4,35 \mu \mathrm{g} / \mathrm{mL}$ kategori sangat kuat. Perbedaan nilai IC50 pada masing-masing ekstrak dan fraksi disebabkan oleh adanya distribusi jenis dan jumlah senyawa metabolit sekunder yang bersifat sebagai antioksidan berdasarkan kepolaran pelarut yang digunakan [14]. Pelarut etanol 80\% (campuran alkohol dan air) memiliki kemampuan yang tinggi untuk mengekstraksi hampir semua senyawa bahan alam [15]. Menurut Harborne (1996), etanol dapat menarik senyawa alkaloid, steroid, saponin, flavonoid, antakuinon, dan glikosida [16]. Tingginya aktivitas antioksidan diduga karena senyawa polifenol dalam ekstrak etanol menghasilkan aktivitas yang kuat dalam menangkap radikal bebas. Polifenol atau flavonoid memberikan kontribusi langsung kepada efek antioksidan, juga memiliki peran dalam mencegah oksidasi lipid [17].

\section{Kesimpulan dan Saran}

Daun jamblang memiliki aktivitas antioksidan yang kuat sampai sangat kuat. Aktivitas yang paling besar dengan parameter IC50 berturut-turut adalah kuersetin, fraksi etil asetat, ekstrak etanol dan fraksi n-heksan. Diharapkan penelitian ini dapat dilanjutkan untuk menguji dengan berbagai parameter seperti antidiabetes, anti aging dan lainnya.

\section{Referensi}

[1] Kementrian Kesehatan RI. (2012). Penyakit Tidak Menular.Buletin Jendela Data dan Informasi Kesehatan.volume 2, semester 2012

[2] Ade Aprilia Surya Putri dan Nurul Hidayati. (2015).Uji Aktivitas Antioksidan Senyawa Fenolik Ekstrak Metanol Kulit Batang Tumbuhan Nyiri Batu (Xylocarpus moluccensis) 1(4), 38

[3] Noya, E., Buang, Y., dan Cunha T.D. (2013). Isolasi, Identifikasi, dan Uji Aktivitas Senyawa Antioksidan Fraksi Kloroform Ekstrak Metanol Sarang Semut (Myrmecodia pendans). Jurnal Kimia Terapan. 1(1), 6-7.

[4] Arifin, Helmi, Anggraini, Nelvi, Handayani, Dian, dan Rasyid, Roslinda. (2006). Standarisasi Ekstrak Etanol Daun Eugenia Cumini Merr. J. Sains Tek. Farmasi.

[5] Ayyanar, M dan Pandurangan, SB. (2012). Syzygium cumini (L.) Skeels: A review of its fitochemical constituents and traditional uses.Asian Pacific Journal of Tropical Biomedicine,240-243.

[6] Ruan, ZP, Zhang, LL and Lin, YM. (2008).Evaluation of the Antioxidant Activity of Syzygium cumini Leaves, Molecules, 13, pp.25452556

[7] WHO. (1992). Quality Control Methods for Herbal Materials. Switzerland: Geneva. 33-35.

[8] Depkes RI. (1995). Materia Medika Indonesia. Jilid keenam. Jakarta: Departemen Kesehatan RI. Halaman 299-305, 334-335.

[9] Ditjen POM RI. (1989). Materia Medika Indonesia. Jilid kelima. Jakarta: Departemen Kesehatan RI. Halaman 169-171.

[10] Farnsworth, N.R. (1996). Biological and Phytochemical Screening of Plants. Journal of Pharmaceutical Sciences. 55 (3). Halaman 263.

[11] Molyneux P. (2004). The use of the stable free radical diphenylpicrylhydrazyl (DPPH) for estimating antioxidant activity. Songklanakarin J. Sci. Technol. 26 (2) : 211-219.

[12] Silalahi, J. (2006).Makanan Fungsional. Yogyakarta: Kanisius. Halaman 38-55.

[13] Cui, Y., Kim, D.S., dan Park, K.C. (2004).Antioxidant Effect InonotusObliquus.J Etnopharmacol.96,79-85.

[14] Huliselan, Y., dan Defny S. W. (2015).Aktivitas Antioksidan Ekstrak Etanol, Etilasetat, dan $n$-Heksan dari Daun Sesewanua (Clerodendron Squamatum Vahl.). Pharmacon Jurnal Ilmiah Farmasi. 4(3): 155-163.

[15] Anonim. (2011).Medicinal Plants of the Myrtaceae: Psidium, Pimenta and Syzygium. http://shodhganga.inflibnet.ac.in/bitstream/10603/60652/15/15_chapter\%2011.pdf. Halaman 94-103.Diakses pada 15 September 2017

[16] Harborne, J.B. (1996). Metode fitokimia Penuntun Cara Modern Menganalisa Tumbuhan. Edisi Kesebelas. Bandung: Penerbit ITB.

[17] Sannigrahi, dkk. (2010). Antioxidant Potential of Crude Extract and Different Fractions of Enhydra fluctuans Lour. Iranian Journal of Pharmaceutical Research. 9(1): 75-82 